\title{
The Study of Improved Fault Petri Nets Diagnosis and Its Application
}

\author{
Xiaozhong Li*, Peng Zhao, Ying Liu, Xiaoqin Liu \\ ${ }^{1}$ College of Computer Science and Information Engineering, Tianjin University of Science and \\ Technology, Tianjin, 300222, China \\ *email: lixz@tust.edu.cn
}

Keywords: Improved fault Petri nets; Network fault array; Fault propagation path; State equation

\begin{abstract}
The purpose of this study is to improve the efficiency of fault diagnosis and quickly aim fault propagation path. This paper introduces the modeling and reasoning methods of Improved Fault Petri Nets (IFPN) based on existing concept and method of modeling for fault Petri nets. IFPN shows network fault array and has the advantages of fault petri nets. By analyzing the dynamic characteristics of the Improved Fault Petri Nets (IFPN), transition enable rule and firing rule can be defined. In terms of characteristic of fault propagation, the analysis shows improved state equation and algorithm for diagnosis can conveniently and quickly target the path of fault propagation. The paper also introduces applying the algorithm in small network fault, and the results from application can prove the accuracy and practicability of the algorithm. The application can help people to research and explore in network fault diagnosis area.
\end{abstract}

\section{Introduction}

The faults of equipment are various. Some of faults can be detected directly because of obvious behaviors and characteristics. However, equipment faults [1] have characteristics of hierarchy, dissemination, relevance, delay and uncertainty etc. As a result, the diagnoses of problems become difficult. Petri net [2] was proposed by Carl Adam Petri as a generic modeling tools in the early stage. Petri net can describe the relationship between the conditions and events in detail and it has been used in different areas. Faults diagnoses is an important application field of Petri net. According to the concurrency features of faults, a fault Petri net of oriented fault diagnosis can be defined. Fault Petri net shows the diagnostic reasoning method of using state equation and it is easy to realize computer program [3]. A new model of fault Petri net without increasing Petri net tuples is proposed, based on the analysis of problem features [4]. The new model is more convenient to analyze the faults spread. However, some of faults are complicated as there is no simple correspondence between faults and features, especially complicated systems. The solution is dividing network into several sub-network by Petri net and studying the subnet to make network more convenient [5]. Fault Petri net model of diagnoses area is established to avoid the limitation of diagnoses problems described by traditional Petri net [6]. The model expands traditional Petri net and combines with the features of the equipment faults spread [7].

In order to improve the efficiency of faults diagnoses and find fault propagation path easily and quickly, a kind of improved fault Petri net model and reasoning method [8] adapted to the network based on concept and model of fault Petri net is proposed in the paper according to the previous studies. The method introduces network fault array and combined with the advantages of fault Petri is described. Transition enable rule and firing rule are defined by analyzing the dynamic characteristics of the Improved Fault Petri Nets (IFPN). Finally, small-scale network fault with example is analyzed to verify the correctness of the algorithm and practicality.

\section{Improved fault Petri nets model}

Fault Petri Nets [9] (FPN) is based on the analysis of the fault propagation characteristic. In order to adapt to the fault evolution of equipment and propagation characteristics, fault petri nets is a new type of petri net which is achieved by redefining the traditional petri net. Directed network 
means fault propagation process. Transition firing is no longer the flow of resources, but it is the fault information of reproduction or derivatives. Fault propagation will not have conflict and collision problems. Propagate process is certain. Abnormal information can be used in multiple transitions, or overlapped, which shows level of severity in fault.

Improved Fault Petri Nets (IFPN) can be defined as follows: a nine tuple: $\sum=(S, T, F, D, W, M, A, B, H)$

$\mathrm{S}$ : $(\mathrm{S}, \mathrm{T} ; \mathrm{F})$ is a network, $\mathrm{S}=\left\{\mathrm{S}_{1}, \mathrm{~S}_{2}, \mathrm{~S}_{3}, \ldots \mathrm{S}_{\mathrm{n}}\right\}$ is a finite non empty set of places. " $\mathrm{S}$ " expresses the states of system. If " $\exists s \in S ", “ s=\{\varnothing\} "$. S is an initial place, which is used to represent the primary abnormal state of the system, such as network port damage, routers do not work, etc. If " $\exists s \in S ", " s s^{\bullet}=\{\varnothing\} " . S$ is a target place, which is used to represent the final state of the system, that is, the system fault.

$\mathrm{T}: \mathrm{T}=\left\{\mathrm{T}_{1}, \mathrm{~T}_{2}, \mathrm{~T}_{3}, \ldots \mathrm{T}_{\mathrm{m}}\right\}$ is a finite non empty set of transitions. " $\mathrm{T}$ " expresses production process of fault events in the system. It reflects the fault propagation phase between the replacements.

Place set and transition set should meet: " $S \cup T \neq \varnothing$ ", " $S \cap T \neq \varnothing$ ". That is, at least a place and transition, and the places and transitions are different types of elements.

$F$ : "F" is a set of network flow relation. It reflects the information flow of the network structure. $F \subseteq(\mathrm{S} \times \mathrm{T}) \cup(\mathrm{T} \times \mathrm{S})$

$$
\begin{aligned}
& \operatorname{dom}(\mathrm{F}) \cup \operatorname{cod}(\mathrm{F})=\mathrm{S} \cup \mathrm{T}, \text { as follows } \\
& \operatorname{dom}(\mathrm{F})=\{s \in S \cup T \mid \exists t \in S \cup T:(\mathrm{s}, \mathrm{t}) \in \mathrm{F}\} \\
& \operatorname{cod}(\mathrm{F})=\{s \in S \cup T \mid \exists t \in S \cup T:(\mathrm{t}, \mathrm{s}) \in \mathrm{F}\}
\end{aligned}
$$

Formula (1) is the domain of "F", and formula (2) is the range of "F".

$\mathrm{D}: \mathrm{S} \rightarrow\{0,1\}$ is the capacity function of improved fault petri nets. It describes the amount of information in the place.

$\mathrm{W}$ : "W" is the weight function. $\forall w \in W: w \equiv 1$.

$\mathrm{M}$ : "M" is the marking of the flow relation. $\mathrm{M}_{0}=\left\{\mathrm{M}_{0}\left(\mathrm{~S}_{1}\right), \mathrm{M}_{0}\left(\mathrm{~S}_{2}\right), \cdots, \mathrm{M}_{0}\left(\mathrm{~S}_{\mathrm{n}}\right)\right\}$ called initial marking. It is expressed as the initial state of the system.

$\mathrm{H}$ : " $\mathrm{H}$ " is a network fault array of length 2. There are two elements that used to determine whether the place is viewed or marked. The first element is the number 0 (Not be viewed) or place " $s \in S$ "mark "s". The second element is the value of $\mathrm{M}\left(\mathrm{S}_{\mathrm{i}}\right)$. If $\mathrm{M}\left(\mathrm{S}_{\mathrm{i}}\right)=1$ (labeled), $\mathrm{M}\left(\mathrm{S}_{\mathrm{i}}\right)=0$ (not labeled). $H\left(S_{i}\right)=\left[S_{i}, M\left(S_{i}\right)\right]$, indicates that place $S_{i}$ has been viewed and marked.

$A$ : " $A$ " is the incidence matrix of improved fault petri nets. $A=\left[c_{\alpha \beta}\right], c_{\alpha \beta}=W\left(t_{\beta}, s_{\alpha}\right)$. W $\left(t_{\beta}, s_{\alpha}\right)$ is weight coefficient of directed arc of transition $t_{\beta}$ to place $s_{\alpha}$.

$\mathrm{B}$ : " $\mathrm{B}$ " is ignition transition sequence at $\mathrm{k}$ time. It is an $\mathrm{m} \times 1$ column matrix consisting of 1,0 .

\section{The application research of IFPN}

\section{1 dynamic characteristics}

The token of IFPN based on transition enable rule and ignite rule has been happened in the place. This process describes the dynamic activity of Petri nets, and it also shows the emergence and evolution of fault information in the system.

Transition enabled rule. Under the current marking $\mathrm{M}$, transition $\mathrm{T}_{\beta}$ is enabled, only when:

$\forall s_{\alpha} \in \cdot T_{\beta}: \quad M\left(s_{\alpha}\right) \geq W\left(s_{\alpha}, T_{\beta}\right)$

Equation (3) is the condition that transition enable occur.

Transition firing rule. At the moment " $i$ ", transition $T_{\beta}$ under the marking $M_{i}$ is enabled, and this transition can fire. When transition $\mathrm{T}_{\beta}$ ignited, we can get the new identity and compute according to the following formula:

$$
\forall s_{\alpha} \in P: \quad M_{i+1}\left(s_{\alpha}\right)=\left\{\begin{array}{ll}
M_{i}\left(s_{\alpha}\right) & s_{\alpha} \notin T_{\beta} \\
M_{i}\left(s_{\alpha}\right) \oplus \mathrm{W}\left(\mathrm{T}_{\beta}, \mathrm{s}_{\alpha}\right) & s_{\alpha} \in T_{\beta}
\end{array} .\right.
$$


$\mathrm{M}_{\mathrm{i}}\left(\mathrm{s}_{\alpha}\right)$ is marking of transition $\mathrm{s}_{\alpha}$ at the moment " $\mathrm{i}$ ", and $\mathrm{T}_{\beta}(\mathrm{i})$ had fired of transition $\mathrm{T}_{\beta}$ at the moment "i". We know that the front fault will not disappear after fault event occurrence, so it conforms to the nature of the fault propagation unlike traditional Petri nets.

\section{2 diagnosis reasoning of IFPN}

In traditional Petri net, incidence matrix is described the basic structure of Petri net. However, in IFPN, it is used to describe the process of fault propagation and the relationship between fault events.

Traditional Petri net defining incidence matrix can use a matrix $A=\left[a_{i j}\right]_{n \times m} . A^{+}=\left[a_{i j}^{+}\right]_{n \times m}$, $A^{-}=\left[a_{i j}^{-}\right]_{n \times m}$ : they are output matrix and input matrix respectively[12].

Set $\sum=\left(\mathrm{S}, \mathrm{T} ; \mathrm{F}, \mathrm{M}_{0}\right)$ is a Petri net. Initial marking is $\mathrm{M}_{0}$, incidence matrix is A. If $M \in R\left(\mathrm{M}_{0}\right)$, the existence of nonnegative integer $\mathrm{n}$ dimensional vector $\mathrm{X}$, makes:

$M=M_{0}+A^{T} X$

(5) is state equation of Petri net. $A^{T}$ is transpose matrix of $A$, and defined as a incidence matrix.

The traditional incidence matrix and state equation is not suitable for transition firing result of IFPN, so incidence matrix and state equation of IFPN should be redefined.

State equation. $M_{k+1}=M_{k} \oplus(\mathrm{A} \otimes \mathrm{B})$

When transition is igniting in IFPN to make the equation of state in line with the failure propagation properties, we introduce two operators" $\oplus$ "and" $\otimes "$.

“ $\oplus ": \forall \mathrm{e}, \mathrm{f}, \mathrm{g} \in R^{1 \times n}: \mathrm{g}=\mathrm{e} \oplus f \quad \mathrm{~g}_{\alpha}=\vee\left(\mathrm{e}_{\alpha}, \mathrm{f}_{\alpha}\right) \quad 1 \leq \alpha \leq \mathrm{n}$

“ $\otimes$ ": set $A \in R^{\mathrm{n} \times \mathrm{m}}, \quad B \in R^{\mathrm{n} \times 1}$, then

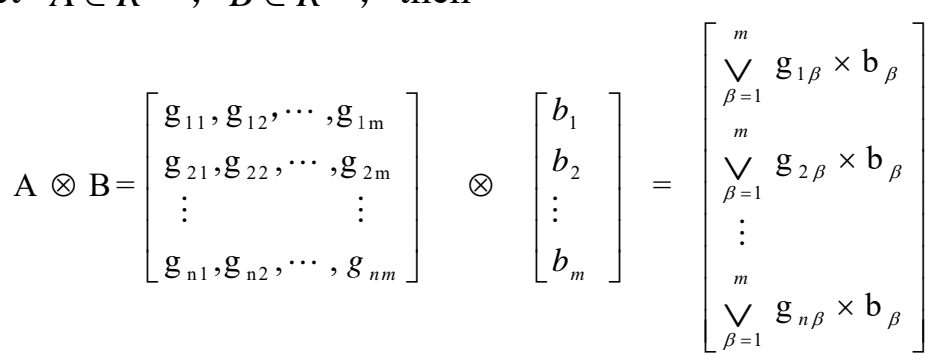

After transition firing, no matter any mark, any place token value can only be 0 or 1 in this state equation.

\section{3 diagnosis algorithm of IFPN}

In IFPN, initial marking of input place may be indicated as a sign of fault. If the fault symptoms appear, the input place contains a token, otherwise the place is empty. Final marking of the solution can be achieved through the IFPN reachability and state equation. Algorithm is as follows:

Step 1: According to the instance equipment system fault, then we can establish the corresponding Petri net model to analyze.

Step 2: according to the instance, we can get starting place and object place collection of IFPN.

Step 3: if initial marking " $\mathrm{M}_{0}$ " of IFPN was confirmed, we can find out the incidence matrix " $\mathrm{A}$ ".

Step 4: The current marking " $M$ " gets transition firing sequence according to transition enabled rules .If $\mathrm{T}_{\alpha}$ can fire, it will go to step 5 , otherwise to step 7.

Step 5: when $\mathrm{t}=\mathrm{i}$, transition $\mathrm{T}_{\alpha}$ fired, new marking $\mathrm{M}_{\mathrm{i}+1}$ will get according to transition firing rule or state equation.

Step 6: set $\mathrm{t}=\mathrm{t}+1$, go to step 4 .

Step 7: the final marking is a result of the system state. This marking will determine whether the target place include token. If it has, fault happened, otherwise will not occur.

According to the first element of $\mathrm{H}$ value of object place, we can reverse track to find the main path. The first element is 0 (Not be viewed) or mark "s" of place $s \in S$. The second element is the corresponding value of $\mathrm{M}(\mathrm{Si})$, if $\mathrm{M}(\mathrm{Si})=1$ (labeled), $\mathrm{M}(\mathrm{Si})=0$ (not labeled). $\mathrm{H}\left(\mathrm{S}_{\mathrm{i}}\right)=\left[\mathrm{S}_{\mathrm{i}}, \mathrm{M}\left(\mathrm{S}_{\mathrm{i}}\right)\right]$, it said that place $S_{i}$ has been viewed and labeled. The factors on the path are place of the path, which is the main factor of the network fault. 


\section{Application examples and analysis}

Nowadays, the development of the network increases rapidly, network fault becomes much more complicated than before. Therefore, people put much more attention on it. Figure 3.1 is a fault Petri net model diagram based on a small fault network. The fault symptoms are as follows: $\mathrm{S}_{1}, \mathrm{~S}_{2}, \mathrm{~S}_{3}, \mathrm{~S}_{4}$, $\mathrm{S}_{5}, \mathrm{~S}_{6}, \mathrm{~S}_{7}, \mathrm{~S}_{8} ; \mathrm{S}_{9}, \mathrm{~S}_{10}, \mathrm{~S}_{11}$ as intermediate events; $\mathrm{S}_{12}$ as object fault.

Assume that the initial marking is $S_{7}$, we can start fault propagation analysis. Analysis the diagnosis process is as follows:

Step 1: according to the instance to establish fault Petri nets, fig. 3.1.

Step 2: initial place collection for $\left\{\mathrm{S}_{1}, \mathrm{~S}_{2}, \mathrm{~S}_{3}, \mathrm{~S}_{4}, \mathrm{~S}_{5}, \mathrm{~S}_{6}, \mathrm{~S}_{7}, \mathrm{~S}_{8}\right\}$, object place collection for $\left\{\mathrm{S}_{12}\right\}$.

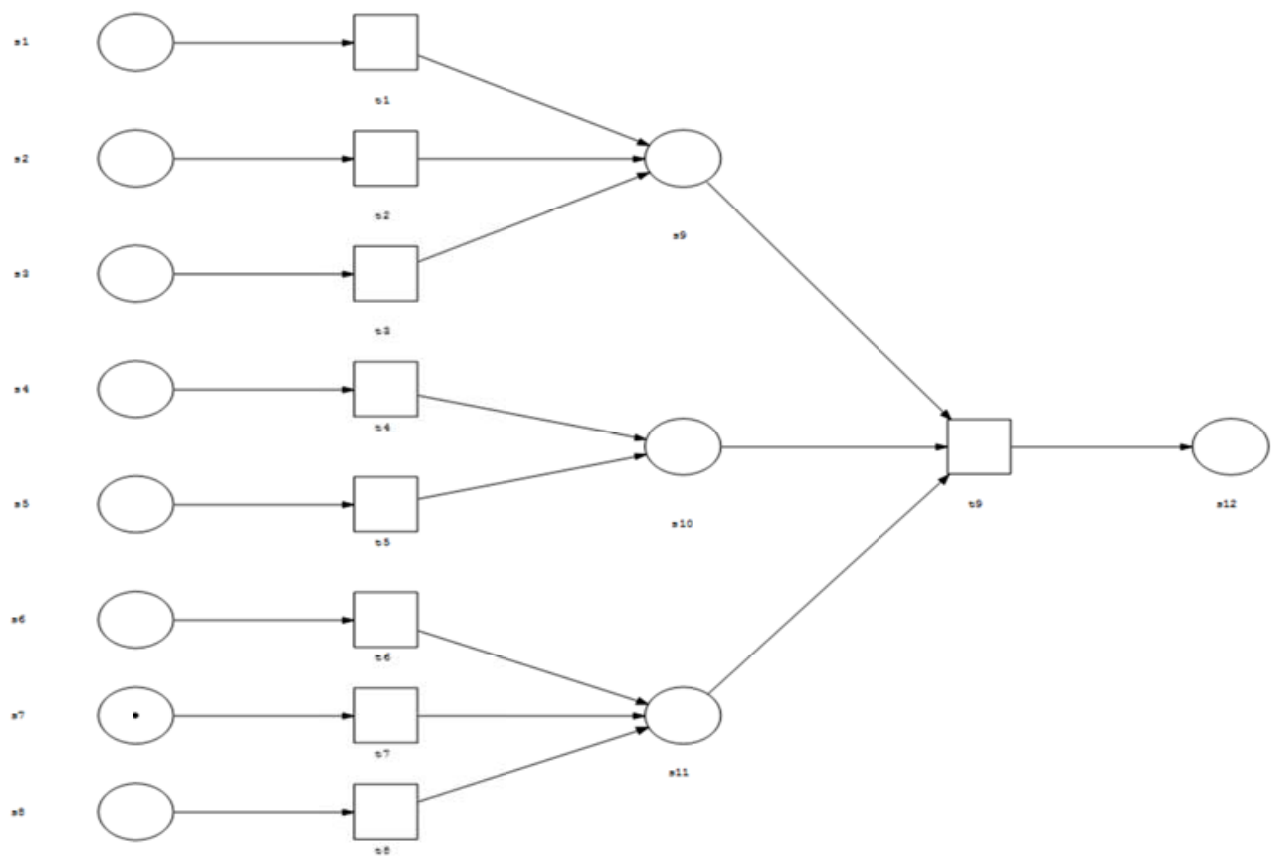

Fig. 3.1. IFPN model.

Table 1 the meaning of transitions and places in IFPN model

\begin{tabular}{|cc|cc|}
\hline place & meaning & transition & meaning \\
\hline $\mathrm{S}_{1}$ & card damaged & $\mathrm{t}_{1}$ & Caused the network lagged \\
$\mathrm{S}_{2}$ & Network intermediate relay too many & $\mathrm{t}_{2}$ & Caused the network lagged \\
$\mathrm{S}_{3}$ & Cable more than topology allows length & $\mathrm{t}_{3}$ & Caused the network lagged \\
$\mathrm{S}_{4}$ & have network routing & $\mathrm{t}_{4}$ & Network performance decline \\
$\mathrm{S}_{5}$ & The bridge or routing buffer overflow & $\mathrm{t}_{5}$ & Network performance decline \\
$\mathrm{S}_{6}$ & Network cable torsion & $\mathrm{t}_{6}$ & Early conflicts caused \\
$\mathrm{S}_{7}$ & Too many nodes in the network & $\mathrm{t}_{7}$ & Early conflicts caused \\
$\mathrm{S}_{8}$ & Damage of Ethernet terminal resistance & $\mathrm{t}_{8}$ & Early conflicts caused \\
$\mathrm{S}_{9}$ & Network lagged conflict & $\mathrm{t}_{9}$ & Ethernet failure caused \\
$\mathrm{S}_{10}$ & Network performance decline & & \\
$\mathrm{S}_{11}$ & Network produced early conflicts & & \\
$\mathrm{S}_{12}$ & Ethernet fault occurs & & \\
\hline
\end{tabular}

Step 3: the initial marking of IFPN as $\mathrm{M}_{0}=(0,0,0,0,0,0,1,0,0,0,0,0)$, incidence matrix is as follows: 


$\begin{array}{cccccccccc} & \mathrm{t}_{1} & \mathrm{t}_{2} & \mathrm{t}_{3} & \mathrm{t}_{4} & \mathrm{t}_{5} & \mathrm{t}_{6} & \mathrm{t}_{7} & \mathrm{t}_{8} & \mathrm{t}_{9} \\ \mathrm{~S}_{1} & 0 & 0 & 0 & 0 & 0 & 0 & 0 & 0 & 0 \\ \mathrm{~S}_{2} & 0 & 0 & 0 & 0 & 0 & 0 & 0 & 0 & 0 \\ \mathrm{~S}_{3} & 0 & 0 & 0 & 0 & 0 & 0 & 0 & 0 & 0 \\ \mathrm{~S}_{4} & 0 & 0 & 0 & 0 & 0 & 0 & 0 & 0 & 0 \\ \mathrm{~S}_{5} & 0 & 0 & 0 & 0 & 0 & 0 & 0 & 0 & 0 \\ \mathrm{~S}_{6} & 0 & 0 & 0 & 0 & 0 & 0 & 0 & 0 & 0 \\ \mathrm{~A}=\mathrm{S}_{7} & 0 & 0 & 0 & 0 & 0 & 0 & 0 & 0 & 0 \\ \mathrm{~S}_{8} & 0 & 0 & 0 & 0 & 0 & 0 & 0 & 0 & 0 \\ \mathrm{~S}_{9} & 1 & 1 & 1 & 0 & 0 & 0 & 0 & 0 & 0 \\ \mathrm{~S}_{10} & 0 & 0 & 0 & 1 & 1 & 0 & 0 & 0 & 0 \\ \mathrm{~S}_{11} & 0 & 0 & 0 & 0 & 0 & 1 & 1 & 1 & 0 \\ \mathrm{~S}_{12} & 0 & 0 & 0 & 0 & 0 & 0 & 0 & 0 & 1\end{array}$

Step 4: perform diagnosis algorithm of the fourth step. According to enabled rule, transition $\mathrm{t}_{7}$ can be fired, and firing transition sequence is as follows:

$$
B=[0,0,0,0,0,0,1,0,0]^{T}
$$

Step 5: after transition $t_{7}$ has been fired, based on definition $4, M_{k+1}=M_{k} \oplus(\mathrm{A} \otimes \mathrm{B})$ we can obtain: $\mathrm{M}_{1}=(0,0,0,0,0,0,1,0,0,0,1,0)$.

Step 6: perform diagnosis algorithm of the fourth step. According to enabled rule, transition $t_{9}$ can be fired, and firing transition sequence is as follows:

$$
B=[0,0,0,0,0,0,0,0,1]^{T} \text {. }
$$

Step 7: after $t_{9}$ firing, we can get $\mathrm{M}_{2}=(0,0,0,0,0,0,1,0,0,0,1,1)$ through state equation.

Step 8: perform diagnosis algorithm of the fourth step. According to enabled rule, there is no transition firing, we will end of the cycle.

By the algorithm, we know $\mathrm{M}_{2}=(0,0,0,0,0,0,1,0,0,0,1,1)$, object place $\mathrm{S}_{12}$ has a token and the system have fault. At this time, the value of $\mathrm{M}_{2}$ had got, then we can set the second element value of $\mathrm{H}\left(\mathrm{S}_{12}\right)$ with the value of 1 . Now we got the object place. According to their values reverse backtracking the results to obtain the fault propagation path, we will get the fault propagation paths: $\mathrm{S}_{7} \rightarrow \mathrm{S}_{11} \rightarrow \mathrm{S}_{12}$. Therefore, we validated the feasibility and the practicability of the algorithm.

\section{Conclusion}

Based on fault Petri nets concepts and modeling methods, this paper comes up with model of improved fault Petri nets. We introduced network fault array to analysis the network faults characteristics, according to their values reverse backtracking the results to obtain the fault propagation path. In this paper, the determination of the propagation path is more simple and accurate. The application can help people to research and explore in network fault diagnosis area.

\section{Acknowledgement}

This work was supported by National Natural Science Foundation of China under Grant No. 11301382, and by Tianjin Application Foundation and Advanced Technology Research Project under Grant No. 14JCQNJC00300, by Tianjin Natural Science Foundation in 2016.

\section{References:}

[1] Huang W H, Xia S B, Liu R Y. Equipment fault diagnosis principle, technology and application [M]. Beijing: The Science Publishing Company, 1996.

[2] Yuan C Y. Principle and application of Petri nets [M]. Beijing: Publishing House of Electronics Industry, 2005.

[3] Zhang W. A fault Petri net of oriented fault diagnosis [J]. Journal of Gansu Lianhe University 
(Natural Science Edition), 2010, 24(5):67-70.

[4] Li X Z, Ma Y J, Li J K. A new fault diagnosis method based on Petri net [J]. Journal of Tianjin University of Science \& Technology, 2004, 19(3): 24-26.

[5] Kuang Y C. The simplification technology of Petri net and its application in fault diagnosis of power network [D]. Changsha University of Science \& Technology, 2006.

[6] Zhao Z G, Lv H X, Qian J X. The study of novel algorithm of fault diagnosis with Petri nets [J]. Computer engineering and Applications, 2003, 39(1):86-87,160.

[7] Li X. Research on Fault Diagnosis Technology Based on Petri net and its application in hydraulic system [D]. Tongji University, 2006.

[8] Liu F Z, Jian-Sheng H U, Jian-Nan L I. Method of Fault Diagnosis for SDH Equipment Based on Fault Petri Nets[J]. Journal of Military Communications Technology, 2010, 31(4):10-14.

[9] Wu Z H. Introduction to Petri nets [M]. version1. Beijing: China Machine Press, 2006: 181-209. 